\title{
How Do I Counsel Parents of a Newly Diagnosed Boy with Haemophilia A?
}

\author{
Karin Kurnik ${ }^{1}$ Christoph Bidlingmaier ${ }^{1,2}$ Martin Olivieri ${ }^{1}$ \\ 1 Paediatric Haemophilia Centre, Dr. von Hauner Children's Hospital \\ Munich, LMU, Munich, Germany \\ ${ }^{2}$ Center for Development and Complex Chronic Diseases in Children \\ (iSPZ Hauner), Munich, Germany \\ Address for correspondence Prof. Dr. med. Karin Kurnik, Head of \\ Paediatric Haemophilia Centre, Dr. von Hauner Children's Hospital \\ Munich, LMU, Lindwurmstraße 4, 80337 Munich, Germany \\ (e-mail: Karin.Kurnik@med.uni-muenchen.de).
}

Hämostaseologie 2020;40:88-96.

\begin{abstract}
Keywords

- haemophilia A

- parents

- counselling
\end{abstract}

Zusammenfassung

Schlüsselwörter

- Hämophilie A

- Eltern

- Beratung
With the recent approval of improved therapeutic options for patients suffering from haemophilia A such as the extended half-life, recombinant factor concentrates, non-factor VIII replacement therapies like Emicizumab and after consideration of the currently running clinical trials investigating even more advanced approaches, counselling of parents of a newly diagnosed boy with haemophilia A has not become less demanding. Parents need to be informed about the pathophysiology, the chronic nature and the potential risks that are commonly associated with this disease and its treatment, depending on disease severity. Above all, the safety and efficacy of the medicinal drug(s) to be used are of utmost importance, given the impact of non-virus-inactivated plasma-derived factor concentrates in the $1980 \mathrm{~s}$. As a consequence, the subsequent development and registration of recombinant clotting factors from mammalian, and recently, even human, cell cultures are seen by many as a breakthrough, although, regarding the product-type-dependent development of inhibitors in previously untreated patients, the discussion is still open. Clinical data for the humanised bispecific antibody Emicizumab in paediatric patients below 2 years of age without inhibitors who suffer from severe haemophilia A are currently limited.

Mit der Zulassung der halbwertszeitverlängerten, rekombinanten Faktorkonzentrate, der Zulassung des nicht auf Faktor VIII Substitution basierenden Emicizumab und unter Berücksichtigung der zurzeit laufenden klinischen Studien ist die Beratung der Eltern eines Jungen mit neu diagnostizierter Hämophilie A nicht einfacher geworden. Die Eltern sollten über die Pathophysiologie der Erkrankung und - unter Berücksichtigung der Schwere der Erkrankung - die damit und mit der Behandlung verbundenen Risiken und den chronischen Verlauf informiert werden. Die Sicherheit und Wirksamkeit des zur Behandlung ausgewählten Medikaments ist von allergrößter Bedeutung, vor allem unter Berücksichtigung der Auswirkungen der Gabe nicht virusinaktivierter, plasmatischer Faktorenkonzentrate in den 80-er Jahren. Die darauffolgende Entwicklung rekombinanter Faktorenkonzentrate aus Säugetierzelllinien (und kürzlich aus humanen Zelllinien) wird von vielen als Durchbruch angesehen. Inwieweit dies auch für die Behandlung zuvor unbehandelter Patienten zutrifft und inwiefern es die Entwicklung von Hemmkörpern beeinflusst, ist noch nicht abschlieBend geklärt. Die Menge an klinischen Daten für den humanisierten, bispezifischen Antikörper Emicizumab für pädiatrische Patienten unter 2 Jahren, die an schwerer Hämophilie A ohne Inhibitoren leiden, ist zurzeit noch begrenzt. received

July 31, 2019

accepted after revision

November 4, 2019 (c) 2020 Georg Thieme Verlag KG Stuttgart · New York
DOI https://doi.org/

10.1055/s-0039-3402805.

ISSN 0720-9355. 


\section{Introduction}

This review will inform about the key steps we take when preparing for counselling of parents of a newly diagnosed boy with haemophilia A (HA) and we structured this review similar to the prioritisation of items in our counselling proceeding. First, the basic knowledge of the medical background of HA needs to be present at the centre to successfully provide the required information to the family. The first section lists all critical and necessary medical background information. Second, before counselling, we always remember the stressful situation of the family. Relevant information is reflected in the second section together with a reference towards guidelines and regulations. Third, controversially leading discussions in haemophilia need to be highlighted and explained to the family as detailed as necessary and as precisely as possible to come to well-informed and balanced decisions, summarized in the next two following sections. Finally, the main aspects of our counselling procedure are again put together in the conclusion and listed in -Table 1; both the content in the different sections and -Table 1 complement each other. Due to the complexity of HA, its potential complications, the scientific background and ongoing discussions especially regarding treatment options, in our opinion, we feel it is of advantage to conduct the counselling at specialized haemophilia centres (e.g. European haemophilia treatment centres, EHTCs, or European haemophilia comprehensive care centres, EHCCCs).

\section{Haemophilia A - General Aspects}

HA is a rare, X-chromosomal-recessively inherited bleeding disorder that is caused by a deficiency of coagulation factor VIII (FVIII). ${ }^{1}$ Haemophilia B comprises the lack of coagulation factor IX (FIX). ${ }^{1}$ The first name for haemophilia B was 'Christmas disease', and there is an interesting coincidence of the first patient's name and the date the paper was published. ${ }^{2}$ The incidence of $\mathrm{HA}$ in the general population is approximately $1: 10,000$, while in live male births it is 1 in 5,000 . $^{1}$

Patients suffering from HA clinically present as 'bleeders' ('for this is the name given to them') ${ }^{3}$ and if not treated adequately, patients affected (usual boys) experience spontaneous or excessive bleeding after minor trauma into muscles

Table1 Counselling checklist

\begin{tabular}{|c|c|}
\hline Topic & Details \\
\hline \multicolumn{2}{|l|}{ Haemophilia A (HA) - general aspects } \\
\hline What is HA? & The function of FVIII and the consequences of impairment of function ${ }^{1,6,10}$ \\
\hline Incidence & Incidence of $\mathrm{HA}^{1}$ \\
\hline Clinical picture, manifestation(s) & First bleeds, chronic/usual bleeds ${ }^{1,4,8}$ \\
\hline Bleeding-associated risks & $\begin{array}{l}\text { Short-term risks (e.g. ICH), long-term risks (e.g. arthropathy) and how to prevent } \\
\text { them, } 1,4,8,9,23 \text { consequences for the quality of life }{ }^{5} \text { and risk of detrimental social } \\
\text { impact (e.g. risk for unemployment) if not treated adequately }\end{array}$ \\
\hline Severity & $\begin{array}{l}\text { Bleeding frequency often depending on the remaining clotting factor level in } \\
\text { plasma } \uparrow, 6,10,32\end{array}$ \\
\hline Treatment - individualisation & $\begin{array}{l}\text { Advantages of pharmacokinetic approaches guided by frequency of bleeds }{ }^{33} \text {; con- } \\
\text { sider the suitability of prolonged half-life FVIII concentrates }\end{array}$ \\
\hline Inheritance & Carrier status, $30 \%$ spontaneous mutations ${ }^{1,15-18}$ \\
\hline Diagnosis & $\begin{array}{l}\text { Benefits of early diagnosis and careful taking of history/family history, laboratory } \\
\text { assays, genetic analysis and prediction of inhibitor risk } 1,6,11-44,19-21,26,33\end{array}$ \\
\hline Laboratory, assays & $\begin{array}{l}\text { Variability of assays }{ }^{19,20} \text { (if diverging results in different centres) and consequences } \\
\text { for monitoring }\end{array}$ \\
\hline Genetics & $\begin{array}{l}\text { Investigation of genetic mutation, mutation-associated risks, }{ }^{21} \text { genetic family } \\
\text { counselling, }{ }^{33,34} \text { prenatal options }{ }^{33}\end{array}$ \\
\hline $\begin{array}{l}\text { The manifestation of bleeds, } \\
\text { differentiation of bleeds, } \\
\text { trauma-induced }\end{array}$ & $\begin{array}{l}\text { Differentiation of bleeds (severe/not severe/occult) and first-aid measures in case of } \\
\text { bleeds } 1,4,8-10,23,32 \\
\text { Provide mobile number of on-call physician } 24 / 7^{34}\end{array}$ \\
\hline Treatment - education/information & $\begin{array}{l}\text { Home therapy, self-administration of FVIII concentrates, documentation of product } \\
\text { use, details of the product (German Transfusion Act) and bleeds }{ }^{32-35} \\
\text { The benefit of treatment with FVIII concentrates; prophylaxis vs. on-demand } \\
\text { treatment }{ }^{24,25} \\
\text { Inhibitor risk, }{ }^{26} \mathrm{ITT} \text {, the burden for the family }{ }^{27} \\
\text { New products, extended half-life FVIII, Emicizumab, clinical trials need to be discussed } \\
\text { in detail ('challenges associated') } \\
\text { Subcutaneous vaccinations }{ }^{36} \\
\text { Treatment beside factor substitution (e.g. physical therapy, pain management) } \\
32,34,36\end{array}$ \\
\hline
\end{tabular}

(Continued) 
Table1 (Continued)

\begin{tabular}{|c|c|}
\hline Topic & Details \\
\hline \multicolumn{2}{|c|}{ Counselling of parents of a boy newly diagnosed with HA } \\
\hline Psychosocial burden & $\begin{array}{l}\text { The burden of the disease, provide contact details of the centre, psychologist, social } \\
\text { worker and communicate carefully }{ }^{31}\end{array}$ \\
\hline Guidelines, recommendations & Refer to existing guidelines and recommendations ${ }^{32-35}$ \\
\hline Team introduction & $\begin{array}{l}\text { Introduce yourself, haemophilia nurse, other physicians/nurses of the haemophilia } \\
\text { team, physical therapist, social worker (e.g. supporting necessity or possibility of a } \\
\text { handicapped ID application if indicated), psychologist }{ }^{32-34}\end{array}$ \\
\hline $\begin{array}{l}\text { Benefits of European haemophilia } \\
\text { comprehensive care centres } \\
(\text { EHCCCs })^{34}\end{array}$ & $\begin{array}{l}\text { Co-ordination of delivery of haemophilia services (hospital/community/affiliated } \\
\text { European haemophilia treatment centres, EHTCs) } \\
\text { 24-hour advisory service for patients, families, hospital doctors, general practitioners } \\
\text { and affiliated EHTCs' health care professionals }{ }^{34} \\
\text { Specialist care for patients with inhibitors, including surgery }{ }^{34} \\
\text { Diagnostic and reference laboratory service with a full repertoire of tests for the } \\
\text { diagnosis and monitoring of inherited disorders of haemostasis } \\
24 \text {-hour laboratory service for clotting factor assays and inhibitor screens }{ }^{34} \\
\text { Access to orthopaedic and/or rheumatological service with provision of surgery } \\
\text { Access to physical therapy service } \\
\text { Access to a specialized obstetric and gynaecological service for the management of } \\
\text { haemophilia carriers and women with von Willebrand disease and other hereditary } \\
\text { bleeding disorders }{ }^{34} \\
\text { Access to paediatric facilities if children are treated } \\
\text { Access to a genetic diagnosis service providing also carrier detection and antenatal } \\
\text { diagnosis } \\
\text { Access to dental service } \\
\text { Access to hepatology and infectious disease service for patients with HIV and/or viral } \\
\text { hepatitis } \\
\text { Professional psychological support } \\
\text { Access to the social worker and welfare advice } \\
\text { Collating of data (e.g. product usage, patient demographics) } \\
\text { Participation in research, including clinical trials }\end{array}$ \\
\hline \multicolumn{2}{|c|}{ Challenges associated with counselling - choice of factor concentrate } \\
\hline $\begin{array}{l}\text { Virus safety of clotting factor } \\
\text { concentrates }\end{array}$ & $\begin{array}{l}\text { Refer to challenges with virus safety in the past and differences between } \\
\text { plasma-derived }(p d) \text { and recombinant }(r) \text { products regarding theoretical } \\
\text { risk of transmission of unknown viruses } s^{37,38} \\
\text { Today's products are considered to be safe }{ }^{38}\end{array}$ \\
\hline Inhibitors & $\begin{array}{l}\text { Explain inhibitors and risks for inhibitor development }{ }^{21,26,27,38} \\
\text { Pd vs. rFVIII; scientific, product-related inhibitor discussion, MASAC }{ }^{39} \text { statement, } \\
\text { SIPPET } \\
\text { Explain the hypothesis behind the use of pd-high VWF clotting factor concentrates in } \\
\text { PUPs }^{40}\end{array}$ \\
\hline \multicolumn{2}{|c|}{ Challenges associated with counselling - new treatment options } \\
\hline New treatment options & $\begin{array}{l}\text { Inform about anti-TFPI, Fitusiran and gene-therapy clinical trials }{ }^{41} \\
\text { Discuss Emicizumab's use in paediatrics (no data for patients }<1 \text { year of age in } \\
\text { SmPC, }{ }^{28} \text { haemostatic system of this patient group not fully developed, }{ }^{28,47} \\
\text { monitoring is challenging) }\end{array}$ \\
\hline \multicolumn{2}{|l|}{ Conclusion } \\
\hline Treatment - economic aspects & Inform about careful and economical use of factor product ${ }^{33,36}$ \\
\hline Medical, other & $\begin{array}{l}\text { Explain the sense of having contact details of other (external) physicians involved, such } \\
\text { as general practitioner, paediatrician, dentist, ear, nose and throat specialist, other }{ }^{34}\end{array}$ \\
\hline Social & $\begin{array}{l}\text { Explain the information need of the kindergarten team, pre-school team, etc. }{ }^{32} \\
\text { Emphasize sports recommended for haemophilia patients }{ }^{32}\end{array}$ \\
\hline Network & $\begin{array}{l}\text { Provide the contact details for contact person(s) of patient organization(s) } \\
\text { Highlight group-fostering activities such as haemophilia camps, meetings of parents } \\
\text { of children with haemophilia and other initiatives }\end{array}$ \\
\hline
\end{tabular}

Abbreviations: FVIII, factor VIII; ICH, intracranial haemorrhage; ITT, immune tolerance therapy; MASAC, Medical and Scientific Advisory Council; PUP, previously untreated patient; SIPPET, Survey of Inhibitors in Plasma-Product Exposed Toddlers; SmPC, summary of product characteristics; TFPI, tissue factor pathway inhibitor; VWF, von Willebrand factor. 
and joints. ${ }^{1}$ Chronic bleeding into joints leads to haemophilic arthropathy, ${ }^{4}$ resulting in reduced functionality, reduced range of motion and chronic pain, all finally causing disability. In a recent study ${ }^{5}$ from France and the United Kingdom, the presence of more than two target joints (target joint: single joint that per definition presents with three- or more spontaneous bleeds within a consecutive 6-month period), ${ }^{6}$ occurrence of joint surgery and increased joint-pain frequency were independent predictors of lower quality of life. ${ }^{5}$ The presence of severe haemophilia has a negative impact on the social status and quality of life. ${ }^{7}$ Results from a study conducted by Pabinger and co-workers showed that, compared with their healthy controls, a significantly lower portion of haemophilia patients was in the active work process, and a higher rate was unemployed or already in early retirement. ${ }^{7}$ In addition to that, lower average values in the quality-of-life scores for physical functioning, role physical, bodily pain, general health and social functioning had been identified using the short-form 36 (SF-36). ${ }^{7}$

Besides the long-term effects of suboptimally treated haemophilia, intracranial haemorrhage (ICH) could be the first bleeding manifestation in 1 to $4 \%$ of patients. ${ }^{8}$ It may happen without having established the diagnosis of haemophilia, especially in a child without a family history of haemophilia, as ICH in a newborn is often associated with delivery ${ }^{9}$ and other concomitant risk factors such as prematurity or asphyxia. Despite the use of prophylaxis, the mortality caused by ICH is still around $20 \%$, and it is more frequent in children equal to or below 2 years of age. ${ }^{9}$

Therefore, the therapeutic objective is to avoid ICH as well as chronic bleeding into joints, and, most of the times, risk of bleeding correlates with severity of haemophilia.

Haemophilia presents either as severe (plasma activity of coagulation factor of $<1$ international units per decilitre; $\mathrm{IU} / \mathrm{dL})$, moderate $(1-5 \mathrm{IU} / \mathrm{dL})$ or mild $(>5-40 \mathrm{IU} / \mathrm{dL}){ }^{10}$ In general, the lower the plasma FVIII activity, the more severe the disease and the more frequent bleeding episodes manifest. However, the severity of haemophilia not always matches the clinical picture, and although patients suffered from severe haemophilia, in 10 to $15 \%$, their bleeding phenotype was mild. ${ }^{11,12}$ And, to what extent increased FVIIItrough levels and with that pharmacokinetic effects are protective again is, as recently published, currently in discussion, as bleeding did not correlate with more time spent below certain clotting factor levels, ${ }^{13}$ although previous models showed a decline in bleeding with an increase of factor activity, ${ }^{14}$ which supports the value of conducting individualised, pharmacokinetic studies prior to starting prophylaxis.

As it became evident that $\mathrm{HA}$ is a potentially debilitating disease, treating physicians need to know the mode of inheritance. Not all cases arise due to heredity; approximately 30\% result from spontaneous mutation. ${ }^{1}$ The mother (called 'carrier') usually passes the disease to her son, and the chance that sons from haemophilia carriers have the disease is $50 \% .{ }^{15}$ Daughters may inherit the disease with a likelihood of $50 \%$ and the daughter affected 'carries' the altered X-chromosome. ${ }^{15}$ The bleeding manifestation of carriers is not uniform, and carriers must not have subnormal FVIII plasma activity levels $<40 \mathrm{IU} / \mathrm{dL}$ to experience bleeding symptoms such as epistaxis, easy bruising, menorrhagia, and post-operative surgical and dental bleeding. ${ }^{16}$ However, compared with boys suffering from, e.g., severe haemophilia, female carriers of haemophilia experience usually a mild bleeding phenotype. ${ }^{16}$ Bleeding symptoms similar to boys with severe haemophilia do exist in females who suffer from severe or moderate haemophilia with FVIII or FIX mutations and extremely skewed X-chromosome inactivation patterns, but these cases are sporadic. ${ }^{17,18}$

The approach towards the diagnosis of HA relies on an accurate patient and family history, the clinical presentation and subsequent laboratory investigations. As already mentioned, the clinical presentation not always follows FVIII plasma activity. ${ }^{11,12}$ And, to make things even more complicated, laboratory results can depend on the assays and reagents used resulting in varying assay results. ${ }^{19}$ Depending on the test used, divergent FVIII activity results in the case of mild HA can occur, potentially resulting in a misdiagnosis of the HA phenotype. ${ }^{20}$ The investigation of the underlying genetic mutation usually completes the laboratory work-up, asking for a separate informed consent and additionally providing, depending on the type of mutation, information about the risk for generation of antibodies against FVIII (e.g. inhibitors) after FVIII substitution. ${ }^{21}$

Like we stated before, most cases are inherited, and as a consequence, the disease is known (usually to the mother who is the carrier), although circumstances exist where this is not the case. ${ }^{22}$ Parents in this situation typically seek our advice before or shortly after the birth of the first child or before or shortly after the birth of the second/third child. The situation is different where HA is not known to the parents, and the patient presented at the haemophilia centre is usually the consequence of the first bleeding manifestation, the situation we focus on here.

The most common first bleeding manifestation of haemophilia patients investigated in a study from the Jodhpur region comprised posttraumatic $(N=20)$ and gum bleeds $(N=17)$, followed by skin bleeds, joint bleeds and epistaxis $\left(N=4\right.$ each). ${ }^{8}$ These were different from the typical presentations, where skin, joint and muscle bleeds were most common. ${ }^{8}$ Like we said before, severe haemophilia may present with ICH as the only presenting feature in newborns in 1 to $4 \%{ }^{8}$ The prophylactic administration of the coagulation factor significantly reduced the risk of cerebral bleeding in patients with severe haemophilia without human immunodeficiency virus (HIV) and inhibitor in a study investigating 10,262 haemophilia patients $\geq 2$ years of age. ${ }^{23}$ Around $41 \%$ of patients built the paediatric/adolescent age group (2-15 years of age) in this study. ${ }^{23}$

The mainstay of therapy of patients suffering from haemophilia, especially from severe haemophilia, is the prophylactic substitution of the missing factor, called 'prophylaxis'. ${ }^{6}$ Two randomized trials have demonstrated its benefit. ${ }^{24,25}$ However, and depending on several risk factors, during substitution of the missing clotting factor, patients may develop inhibitors. ${ }^{26}$ Inhibitors may interfere with the functional activity of FVIII, thus putting the patients again at the risk of bleeding despite FVIII substitution, which asks for 
immune tolerance therapy (ITT) or, if not successful, for bypassing therapy, which puts a tremendous burden on the patient and his family. ${ }^{27}$ With the global registration of the bispecific monoclonal antibody Emicizumab for haemophilia patients with inhibitors, a new therapeutic option is now available for these patients. ${ }^{28}$

The discussion to what extent plasma-derived (pd) FVIII products cause fewer inhibitors compared with recombinant FVIII (rFVIII) concentrates is ongoing. However, based on the results of the recently conducted, randomized Survey of Inhibitors in Plasma-Product Exposed Toddlers (SIPPET) study, ${ }^{29}$ post-hoc analyses of surveys of United States Haemophilia and Thrombosis Research Society members showed that 44/54 US physicians were considering to change their current practice with 31/44 physicians using pd FVIII for previously untreated patients (PUPs). ${ }^{30}$ In their conclusion, Sande et al state that the results of the two consecutive surveys indicated that the SIPPET study and its post-hoc analyses had influenced clinical practice in the United States over the survey period of around 20 months, mainly about considering von Willebrand factor (VWF)-containing pd FVIII for PUPs. ${ }^{30}$

\section{Counselling of Parents of a Newly Diagnosed Boy with Haemophilia A}

Before meeting with the parents of a boy with newly diagnosed $\mathrm{HA}$, one should be aware that caring for a son/brother suffering from haemophilia can be associated with significant stress and even traumatic experiences for all family members (especially in the case of severe haemophilia with inhibitors, need for ITT or a parental history of unfairly suspected child abuse). In line with this, a dedicated 'psychosocial care' approach has recently been published by Limperg et al. ${ }^{31}$ As a consequence, before a counselling procedure takes place at our centre, all of our team members make sure to adhere to a careful, reflective and diligent counselling.

An essential part of our counselling is the adherence to published standards in the management of haemophilia, such as the standards published by the World Federation of Hemophilia (WFH). ${ }^{32}$ As a consequence (and having in mind the psychosocial burden), during counselling of parents of a boy with newly diagnosed HA, we follow our institutional 'checklist' ( Table 1). Due to the complexity of all aspects involved, treatment of patients with severe haemophilia should take place at designated EHTCs or EHCCCs ${ }^{33,34}$ and compliance with local guidelines and recommendations is a must. ${ }^{35}$ Explaining the requirements needed to be present at the centre for receiving the EHTC or EHCCC status is an excellent opportunity to bring the 'team' (family and centre staff) together (shared decision making). ${ }^{36}$

\section{Challenges Associated with Counselling - Choice of Factor Concentrate}

In the following, we would like to reflect critically on the medical-scientific information we take into consideration when it comes to informing parents on product selection and new treatment options, as these two topics bear the potential for controversial discussion in the haemophilia medical community (e.g. preference of pd FVIII with high VWF content in PUPs over rFVIII concentrates, use of Emicizumab in paediatric patients without inhibitors or use of extended half-life FVIII concentrates for prophylaxis).

Due to the implementation of virus-inactivation and effective surveillance procedures, pd FVIII clotting factor concentrates no longer carry the risk of transmitting hepatitis C or HIV, as this happened with non-virus-inactivated clotting factor concentrates primarily in the 1980 s. $^{37}$ Today, all clotting factor concentrates are considered to be safe. ${ }^{38}$ Regarding pd clotting factor concentrates, the transmission of pathogens cannot be entirely excluded. ${ }^{38}$ This statement includes unknown viruses and other pathogens. ${ }^{38}$ Such a statement is not part of the prescribing information of recombinant clotting factors from the third generation onwards. ${ }^{38}$

Currently, the most severe and relevant adverse reaction is the development of inhibitors. ${ }^{21,26,27,38}$ Inhibitor incidences vary from product to product. Regarding recombinant factor concentrates, they can range from $26 \%$ up to nearly $50 \%{ }^{38}$ The discussion to what extent pd factor concentrates should be preferred in PUPs with severe HA (SHA) until the reach of what exposure day (ED) is still open.

Based on this and the results of the SIPPET ${ }^{29}$ study, the Medical and Scientific Advisory Council (MASAC) of the United States National Hemophilia Foundation has issued MASAC Document \#243. ${ }^{39}$ The MASAC recommends individuals with greater than 50 EDs to any recombinant product and individuals with more than zero and less than 50 EDs to stay on their current recombinant product. ${ }^{39}$ For individuals with a new diagnosis of haemophilia, a careful risk/benefit evaluation between the caregiver and patient should take place, considering the options to initiate therapy with a pd VWF/FVIII product in all PUPs. ${ }^{39}$ Alternatively, treatment is started with a recombinant FVIII product as previously recommended by MASAC or with a 'newer' rFVIII product, which may provide an opportunity for the use of new, extended half-life FVIII products in paediatric patients. ${ }^{33,39}$ However, currently only two prolonged half-life FVIII products have been registered in the European Union (EU) for the use in children below the age of 12 years, and so far, no data on the use of these products in PUPs with SHA are available from peer-reviewed journals. Additionally, compared with extended half-life FIX concentrates, the prolongation of half-life of FVIII in extended halflife FVIII products in children is less intense and whether or not the generally increased clearance of FVIII in this patient group further reduces this benefit needs discussion.

As we assume here that the respective patient concerned is a PUP, our recommendation for treatment follows the MASAC recommendation. ${ }^{39}$ In cases where we expect an increased risk for the development of inhibitors (e.g. null mutations, ${ }^{26}$ large deletions and nonsense mutations, ${ }^{21}$ family history of inhibitors ${ }^{26}$ ), we start the first 50 EDs of treatment with a virus-inactivated, pd, VWF/FVIII concentrate, preferentially with a high VWF content. ${ }^{40}$ 


\section{Challenges Associated with Counselling - New Treatment Options}

With the approval of the humanised, bispecific antibody Emicizumab by the European Medicines Agency (EMA), Emicizumab is now registered and available in Europe for the routine prophylaxis of bleeding episodes in patients with HA (congenital FVIII deficiency) with FVIII inhibitors and SHA (congenital FVIII deficiency, FVIII $<1 \%$ ) without FVIII inhibitors for patients in all age groups, as documented in the summary of product characteristics (SmPC). ${ }^{28}$

More new treatment options currently investigated in clinical trials comprise anti-tissue factor pathway inhibitors (anti-TFPI), an investigational, antithrombin-interferingribonucleic acid (iRNA, Fitusiran) and gene therapy of HA or $\mathrm{HB} \cdot{ }^{41}$ No paediatric subjects below the age of 12 years so far have been included in the anti-TFPI trials yet, while recruitment of patients below the age of 12 years has just started in the phase II/III study of Fitusiran (NCT 03974113). Two gene therapy studies will enrol patients from 2 to 65 years, who suffer from HA or HB (not yet recruiting, NCT03217032 and NCT03961243, in both studies a lentiviral gene therapy approach has been selected). As these therapies will need more years before receiving registration for paediatric patients, we will not discuss these options here.

The mode of action (moa) of Emicizumab is fundamentally different from the moa of activated FVIII (FVIIIa). ${ }^{42}$ Emicizumab recognizes both enzyme factor IXa (FIXa) and the substrate factor $\mathrm{X}(\mathrm{FX}) .^{42}$ By bringing FIXa and FX close, it facilitates FIXa-mediated activation of FX. ${ }^{42}$ In preclinical studies investigating non-human primate models of acquired $\mathrm{HA}$, administration of Emicizumab resulted in haemostatic activities corresponding to a mild HA phenotype. ${ }^{43}$

The use of Emicizumab in paediatric patients can cause neutralizing anti-drug antibodies, as reported for two patients in the paediatric study for Emicizumab (HAVEN 2) ${ }^{43}$ Emicizumab has no on/off mechanism (FVIIIa has), does not bind to phospholipid (FVIIIa does), there is no differentiation between zymogen (FIX) and enzyme (for FVIIla there is, as it is specific for FIXa and FX), it has a low affinity for enzyme and substrate (FVIIla's affinity is high), it is in excess over enzyme and substrate (for FVIIla, enzyme and substrate are in excess over cofactor) and it has a low level of self-regulation (FVIIla has a high level of self-regulation). ${ }^{42}$ We feel it is essential to understand that the activation of the FX-activating complex in the typical setting experiences limitation by the amount of FVIIIa generated during activation of the coagulation cascade, while in the case of Emicizumab it is the amount of FIXa made. It may prove challenging if FIXa is administered externally (e.g. by administration of drugs containing FIXa). ${ }^{42,44}$ These aspects need attention, especially under the consideration of the long half-life of Emicizumab. ${ }^{42}$

Emicizumab is effective at prevention of bleeding (prophylaxis) ${ }^{43}$ However, some patients treated with Emicizumab will experience a bleeding event that requires treatment with an additional haemostatic agent. ${ }^{43}$ Under these circumstances, the administration of, e.g., FVIII, is considered a safe option in non-inhibitor patients receiving Emicizumab. ${ }^{43}$
Also, for Emicizumab, there is a MASAC recommendation (\#255). ${ }^{44}$ Due to a boxed warning regarding the risk of thrombotic microangiopathy and thromboembolism in the context of concomitant use of activated prothrombin complex concentrates to treat breakthrough bleeding in patients receiving Emicizumab, Emicizumab is recommended by the MASAC only to be prescribed by (or in close proximity to) the appropriate staff of the patient's haemophilia treatment centre, which is also recommended for the following bleeding events. ${ }^{44}$ However, and concerning the use of Emicizumab in infants under 6 months of age, there are, according to the MASAC, limited data. ${ }^{44}$

The SmPC for Emicizumab ${ }^{28}$ confirms the missing of clinical data in patients less than 1 year of age. The number of infants and toddlers analysed is five (1 month to less than 2 years of age). ${ }^{28}$ This fact may prove problematic as the median age of starting home treatment in PUPs with SHA in a nationwide real-world study with 700 person-years was 1.1 years. ${ }^{45}$ The median age at diagnosis was 0.7 months and the median age at first exposure to FVIII was 9.0 months. ${ }^{45}$

Due to the need for regular prophylaxis, patients with SHA without inhibitors (e.g. PUPs) belong to the group of patients who would profit most from a potential prophylactic treatment with Emicizumab.

Additionally it is stated in the updated EMA assessment report of Emicizumab that due to the missing of pharmacokinetic data for patients below the age of 1 year, pharmacokinetic simulations had been performed, which indicated for the youngest patients (0-3 months old) median trough concentrations remaining higher than $30 \mu \mathrm{g} / \mathrm{mL}$ for both once weekly (QW) and once every 2 weeks (Q2W) dosing regimens (EMA/ 125963/2019, page 48). ${ }^{46}$ Median trough concentrations slightly below $30 \mu \mathrm{g} / \mathrm{mL}$ were predicted with once every 4 weeks (Q4W) dosing regimen in patients below 6 months of age. In summary, meaningful efficacy with all three dosing regimens is also expected in paediatric patients aged less than 1 year (EMA/125963/2019, page 49). ${ }^{46}$

FVIII inhibitors do not recognize Emicizumab or interfere with its binding to FIXa and FX, so that Emicizumab restores haemostasis to a similar degree in patients with or without FVIII inhibitors, making efficacy, safety and pharmacokinetic results in paediatric patients with inhibitors generalisable to paediatric patients without inhibitors (EMA/125963/2019, page 128). ${ }^{46}$

Extrapolation of pharmacokinetic results from an adult to a paediatric patient population may also be possible due to the similarity of Emicizumab's pharmacokinetics in adult, adolescent and paediatric patients (EMA/125963/2019, pages 130 and 131$){ }^{46}$

No safety risks specific for the paediatric patients receiving Emicizumab were identified (EMA/125963/2019, page 165 ) and collection of additional safety data for the paediatric population will take place via the proposed post-approval safety study. ${ }^{46}$

The statements in the $\mathrm{SmPC}^{28}$ for Emicizumab (paediatric population, 4.4, special warnings and precautions for use, page 8 ) reflect the missing data for children below the age of 1 year. Under consideration of the dynamically and evolving 
development of the haemostatic system in this patient population, and the relative concentrations of pro- and anti-coagulant proteins in these patients, ${ }^{47}$ a recommendation exists for a benefit/risk assessment concerning the use of Emicizumab (e.g. central venous catheter-related thrombosis). ${ }^{28}$

In a recent expert review on Emicizumab for HA without inhibitors, Cafuir et al discuss the use of Emicizumab in PUPs. ${ }^{43}$ Several aspects associated with the potential use of Emicizumab in paediatric patients raise the concerns of the authors. ${ }^{43}$

First, it is not clear if the early administration of Emicizumab, in fact, would delay FVIII exposure ${ }^{43}$ and what the resulting impact is. Whether or not the delayed exposure to FVIII will produce less or more inhibitors in young children needs to be monitored over time. ${ }^{43}$ Second, in patients below the age of 6 months, predicted Emicizumab concentrations in plasma are 19 to $33 \%$ lower compared with older patients. ${ }^{43}$ Third, to what extent simultaneous administration of small FVIII doses and Emicizumab influence inhibitor development needs investigation in a clinical trial. ${ }^{43}$ Also, Cafuir et al refer to the low number of PUPs so far investigated $(N=1)$, supporting longitudinal studies here. ${ }^{43}$ Finally, long-term data regarding a positive effect of Emicizumab on arthropathy and bone density, known from FVIII, are needed. ${ }^{43}$

Monitoring of Emicizumab and FVIII is a challenge. ${ }^{43,48}$ The plasma concentration of Emicizumab can now be explicitly measured. ${ }^{43}$ To obtain information about the overall coagulation profile, the thrombin generation assay, nonactivated rotational thromboelastometry (NATEM) and a novel point-of-care whole blood coagulation assay, ClotChip, are evaluated. ${ }^{43}$

Investigation of these options is ongoing due to the interference of Emicizumab with standard, e.g. one-stage and chromogenic (human reagents), activated partial thromboplastin time (aPTT)-based clotting assays. ${ }^{43,48}$ In case of measurement of the pure FVIII-dependent clotting activity, chromogenic (bovine reagents), aPTT-based clotting assays are the first choice. ${ }^{43,48}$ Due to this and, even more, complicated in the case of existing inhibitors, the commonly used laboratory approaches for measuring FVIII activity do not work out as usual, and again the bovine chromogenic assay is recommended, performed in the case of inhibitors in specialized laboratories only. ${ }^{43,48}$

In summary, due to the limitation of data for paediatric patients with SHA without inhibitors under 2 years of age and not yet investigated or resolved questions associated with the use of Emicizumab, we currently advise the parents not to use Emicizumab if their child is a PUP with SHA without inhibitors. In the case of a child with poor venous access and 'dramatic' family history for inhibitors, we feel that a decision towards the use of Emicizumab can be justified if the alternative would be no prophylaxis instead or implementation of a central venous line, e.g. a port device.

\section{Conclusion}

As outlined in the Introduction, we explore the familial situation and interactions, and we try to match the information we provide to the existing knowledge about haemophilia. In practice, we find that some parents are highly interested and well prepared (which sometimes is a problem itself!), while others tend to listen and will ask their questions later. However, a few points mentioned are similar to all. We always inform the parents about the main character of the disease, namely that HA and, especially SHA, is a rare and chronic disease. Until no further treatment options are available, in PUPs with SHA, economical ${ }^{33,36}$ replacement of the missing factor (referring to prophylaxis as standard) ${ }^{24,25}$ is the state-ofthe-art treatment to prevent spontaneous- or trauma-induced bleeding (e.g. ICH), ${ }^{8,9,23}$ to prevent the development of early haemophilic arthropathy ${ }^{4}$ and to reduce inhibitor risk. ${ }^{49}$ Depending on the history of the patient and his family, the clinical course, the severity of the disease and the genetic analysis, we discuss the different factor concentrates and schedules ( $\mathrm{pd}$, recombinant with or without extended halflife, on-demand and prophylaxis), suitable for the patient.

Besides the medical treatment, other factors such as how to inform other specialities involved and other institutions (e.g. kindergarten, pre-school), to stress the benefit of sports recommended and to provide network contact details (e.g. patient organization, group activities, etc.) are other important, non-purely medical aspects that are often crucial towards coping with this disease.

As long as no more clinical data are available on the use of Emicizumab in children below the age of 2 years with SHA without inhibitors, we generally remain reluctant administering Emicizumab. In line with this, the committee on Coagulation Products Safety, Supply, Access (CPSSA) of the World Federation of Hemophilia asks for clinical studies in this age group to support the indication in patients at this very young age in a recent letter to the editor. ${ }^{50}$

In summary, the counselling of parents of a newly diagnosed boy with HA has become more challenging as regarding the potential use of Emicizumab in paediatric patients below the age of 2 years with SHA without inhibitor improved convenience (e.g. subcutaneous administration) has to be carefully weighed up against safety (e.g. outstanding longterm efficacy and safety data in a representative cohort of this patient group).

However, optimal diagnostic standards and treatment are only one part of the management of haemophilia at our centre and management is complex. As an example of complexity, we referred to the impact haemophilia might have on the other family members. ${ }^{31}$ As a consequence, the management of haemophilia should be in the hands of specialized comprehensive care centres with devoted expert teams and a variety of relevant, specialist departments in immediate reach. ${ }^{33,34}$

Our list may not be complete, or the order of the items prioritised is different at different centres. However, we hope to have provided a concise review of, in our view, the most important aspects when it comes to counselling of parents of a boy with newly diagnosed HA.

Authors' Contributions

K.K. wrote the manuscript, C.B. and M.O. have read and approved the final manuscript. 


\section{Conflict of Interest}

K.K. has received grants, travel support and/or lecture fees from Bayer, Biotest, CSL Behring, NovoNordisk, Roche, Sobi and Shire/Takeda and honoraria for an advisory board from CSL Behring and Shire/Takeda.

C.B. is an investigator for Roche and has received grants and honoraria from CSL Behring, Sobi, Shire/Takeda, Pfizer, Bayer and Biotest.

M.O. has received grants/research support from CSL Behring and Bayer and consultancy fees from Shire/Takeda, Bayer, Biotest, CSL Behring, NovoNordisk, Octapharma, Pfizer, and Sobi plus speaker bureau fees from Shire/Takeda, Bayer, Biotest, CSL Behring, Pfizer and Sobi.

\section{Acknowledgments}

We appreciate medical-English writing and technical assistance support, which was provided by Dr Mathias Jürs Medical Consulting, Frankfurt am Main, Germany.

\section{References}

1 Mannucci PM, Tuddenham EGD. The hemophilias-from royal genes to gene therapy. N Engl J Med 2001;344(23):1773-1779

2 Biggs R, Douglas AR, MacFarlane RG et al. Christmas disease. A condition previously mistaken for haemophilia. BMJ 1952;2 (4799):1378-1382

3 Otto JC. An account of a hemorrhagic disposition existing in certain families. Med Phys J 1808;20(113):69-72

4 van Vulpen LFD, Holstein K, Martinoli C. Joint disease in haemophilia: pathophysiology, pain and imaging. Haemophilia 2018;24 (Suppl 6):44-49

5 Carroll L, Benson G, Lambert J, Benmedjahed K, Zak M, Lee XY. Real-world utilities and health-related quality-of-life data in hemophilia patients in France and the United Kingdom. Patient Prefer Adherence 2019;13:941-957

6 Blanchette VS, Key NS, Ljung LR, Manco-Johnson MJ, van den Berg HM, Srivastava A; Subcommittee on Factor VIII, Factor IX and Rare Coagulation Disorders of the Scientific and Standardization Committee of the International Society on Thrombosis and Hemostasis. Definitions in hemophilia: communication from the SSC of the ISTH. J Thromb Haemost 2014;12(11):1935-1939

7 Hartl HK, Reitter S, Eidher U, Ramschak H, Ay C, Pabinger I. The impact of severe haemophilia on the social status and quality of life among Austrian haemophiliacs. Haemophilia 2008;14(04):703-708

8 Payal V, Sharma P, Goyal V, Jora R, Parakh M, Payal D. Clinical profile of hemophilia patients in Jodhpur Region. Asian J Transfus Sci 2016;10(01):101-104

9 Zanon E, Pasca S. Intracranial haemorrhage in children and adults with haemophilia A and B: a literature review of the last 20 years. Blood Transfus 2019;17(05):378-384

10 White GC II, Rosendaal F, Aledort LM, Lusher JM, Rothschild C, Ingerslev J; Factor VIII and Factor IX Subcommittee. Definitions in hemophilia. Recommendation of the scientific subcommittee on factor VIII and factor IX of the scientific and standardization committee of the International Society on Thrombosis and Haemostasis. Thromb Haemost 2001;85(03):560

11 Santagostino E, Mancuso ME, Tripodi A, et al. Severe hemophilia with mild bleeding phenotype: molecular characterization and global coagulation profile. J Thromb Haemost 2010;8(04):737-743

12 Pavlova A, Oldenburg J. Defining severity of hemophilia: more than factor levels. Semin Thromb Hemost 2013;39(07):702-710

13 Zhou JY, Barnes RFW, Foster G, Iorio A, Cramer TJ, von Drygalski A. Joint bleeding tendencies in adult patients with hemophilia: It's not all pharmacokinetics. Clin Appl Thromb Hemost 2019; 25:1-10
14 den Uijl IE, Fischer K, Van Der Bom JG, Grobbee DE, Rosendaal FR, Plug I. Analysis of low frequency bleeding data: the association of joint bleeds according to baseline FVIII activity levels. Haemophilia 2011;17(01):41-44

15 The Hemophilia, von Willebrand Disease and Platelet Disorders Handbook. How hemophilia is inherited. Available at: https:// www.hog.org/handbook/section/2/how-hemophilia-is-inherited. Assessed October 18, 2019

16 Paroskie A, Oso O, Almassi B, DeBaun MR, Sidonio RF Jr. Both hemophilia health care providers and hemophilia a carriers report that carriers have excessive bleeding. J Pediatr Hematol Oncol 2014;36(04):e224-e230

17 Di Michele DM, Gibb C, Lefkowitz JM, Ni Q, Gerber LM, Ganguly A. Severe and moderate haemophilia A and B in US females. Haemophilia 2014;20(02):e136-e143

18 Radic CP, Rossetti LC, Abelleyro MM, et al. Phenotype-genotype correlations in hemophilia A carriers are consistent with the binary role of the phase between $\mathrm{F} 8$ and X-chromosome inactivation. J Thromb Haemost 2015;13(04):530-539

19 Kitchen S, Signer-Romero K, Key NS. Current laboratory practices in the diagnosis and management of haemophilia: a global assessment. Haemophilia 2015;21(04):550-557

20 Oldenburg J, Pavlova A. Discrepancy between one-stage and chromogenic factor VIII activity assay results can lead to misdiagnosis of haemophilia A phenotype. Hamostaseologie 2010;30 (04):207-211

21 Gouw SC, van den Berg HM, Oldenburg J, et al. F8 gene mutation type and inhibitor development in patients with severe hemophilia A: systematic review and meta-analysis. Blood 2012;119 (12):2922-2934

22 MacLean PE, Fijnvandraat K, Beijlevelt M, Peters M. The impact of unaware carriership on the clinical presentation of haemophilia. Haemophilia 2004;10(05):560-564

23 Witmer C, Presley R, Kulkarni R, Soucie JM, Manno CS, Raffini L. Associations between intracranial haemorrhage and prescribed prophylaxis in a large cohort of haemophilia patients in the United States. Br J Haematol 2011;152(02):211-216

24 Manco-Johnson MJ, Abshire TC, Shapiro AD, et al. Prophylaxis versus episodic treatment to prevent joint disease in boys with severe hemophilia. N Engl J Med 2007;357(06):535-544

25 Gringeri A, Lundin B, von Mackensen S, Mantovani L, Mannucci PM; ESPRIT Study Group. A randomized clinical trial of prophylaxis in children with hemophilia A (the ESPRIT Study). J Thromb Haemost 2011;9(04):700-710

26 Garagiola I, Palla R, Peyvandi F. Risk factors for inhibitor development in severe hemophilia a. Thromb Res 2018;168:20-27

27 Walsh CE, Jiménez-Yuste V, Auerswald G, Grancha S. The burden of inhibitors in haemophilia patients. Thromb Haemost 2016;116 (Suppl 1):S10-S17

28 Annex I. Summary of product characteristics. Available at: https://www.ema.europa.eu/en/documents/product-information/hemlibra-epar-productinformation_en.pdf. Assessed October 18, 2019

29 Peyvandi F, Mannucci PM, Garagiola I, et al. A randomized trial of factor VIII and neutralizing antibodies in hemophilia A. N Engl J Med 2016;374(21):2054-2064

30 Sande CM, Al-Huniti A, Ten Eyck P, Shrathkumar AA. Impact of the Survey of Inhibitors in Plasma-Product Exposed Toddlers (SIPPET) study and its post hoc analyses on clinical practice in the United States: A survey of Haemophilia and Thrombosis Research Society members. Haemophilia 2019;25(05):754-772

31 Limperg PF, Haverman L, Beijlevelt M, et al. Psychosocial care for children with haemophilia and their parents in the Netherlands. Haemophilia 2017;23(03):362-369

32 Srivastava A, Brewer AK, Mauser-Bunschoten EP, et al; Treatment Guidelines Working Group on Behalf of The World Federation of Hemophilia. Guidelines for the management of hemophilia. Haemophilia 2013;19(01):e1-e47 
33 Giangrande PLF, Peyvandi F, O'Mahony B, et al. Kreuth IV: European consensus proposals for treatment of haemophilia with coagulation factor concentrates. Haemophilia 2017;23(03): 370-375

34 European Haemophilia Network. European guidelines for the certification of Haemophilia Centres. Available at: http://www. euhanet.org/docs/euhanet-european_guidelines_for_the_certification_of_haemophilia_centres_2013.pdf. Assessed October 18, 2019

35 Executive Committee of the German Medical Association on the Recommendation of the Scientific Advisory Board. CrossSectional Guidelines for Therapy with Blood Components and Plasma Derivatives. 4th revised and updated ed. Berlin: German Medical Association; 2014. Available at: https://www. bundesaerztekammer.de/fileadmin/user_upload/downloads/ Querschnittsleitlinie_Gesamtdokument-englisch_07032011.pdf

36 Thornburg CD. How I approach: previously untreated patients with severe congenital hemophilia A. Pediatr Blood Cancer 2018; 65(12):e27466

37 Mannucci PM. Viral safety of coagulation factor concentrates: memoirs from an insider. J Thromb Haemost 2018;16(04): 630-633

38 Lassila R, Makris M. Safety surveillance in haemophilia and allied disorders. J Intern Med 2016;279(06):515-523

39 National Hemophilia Foundation. Available at: https://www.hemophilia.org/sites/default/files/document/files/243SIPPET.pdf. Assessed October 18, 2019

40 Dasgupta S, Repessé Y, Bayry J, et al. VWF protects FVIII from endocytosis by dendritic cells and subsequent presentation to immune effectors. Blood 2007;109(02):610-612

41 Mahlangu J, Cerquiera M, Srivastava A. Emerging therapies for haemophilia - Global perspective. Haemophilia 2018;24(Suppl 6): $15-21$

42 Lenting PJ, Denis CV, Christophe OD. Emicizumab, a bispecific antibody recognizing coagulation factors IX and $\mathrm{X}$ : how does it actually compare to factor VIII? Blood 2017;130(23): 2463-2468

43 Cafuir L, Kruse-Jarres R, Mancuso ME, Kempton CL. Emicizumab for hemophilia A without inhibitors. Exp Rev Hematol 2019; 12 (07):515-524

44 National Hemophilia Foundation. Available at: https://www.hemophilia.org/Researchers-Healthcare-Providers/Medical-andScientific-Advisory-Council-MASAC/MASAC-Recommendations/ Recommendation-on-the-Use-and-Management-of-Emicizumab-kxwh-Hemlibra-for-Hemophilia-A-with-and-withoutInhibitors. Assessed October 18, 2019

45 Vepsäläinen K, Riikonen P, Lassila P, et al. Long-term clinical and economic outcomes in previously untreated paediatric patients with severe haemophilia A: A nationwide real-world study with 700 person-years. Haemophilia 2018;24(03):436-444

46 EMA. Assessment report. Available at: https://www.ema.europa. eu/en/documents/variation-report/hemlibra-h-c-4406-ii-0002epar-assessment-report-variation_en.pdf. Assessed October 18, 2019

47 Andrew M, Paes B, Milner R, et al. Development of the human coagulation system in the full-term infant. Blood 1987;70(01): 165-172

48 Adamkewicz JI, Chen DC, Paz-Priel I. Effects and interferences of Emicizumab, a humanised bispecific antibody mimicking activated factor VIII cofactor function, on coagulation assays. Thromb Haemost 2019;119(07):1084-1093

49 Gouw SC, van der Bom JG, Marijke van den Berg H for the CANAL study group. Treatment-related risk factors of inhibitor development in previously untreated patients with hemophilia $A$ : the CANAL cohort study. Blood 2007;109(11):4648-4654

50 Pierce GF, Hart DP, Kaczmarek R; Committee on Coagulation Products Safety Supply, Access (CPSSA) of the World Federation of Hemophilia (WFH). Safety and efficacy of emicizumab and other novel agents in newborns and infants. Haemophilia 2019; 25(05):e334-e335 